\title{
Mollenhauer's Representation: The Role of Preservice Teachers in the Practices of Upbringing
}

\author{
Andrew Foran and Daniel B. Robinson \\ St. Francis Xavier University
}

\begin{abstract}
Our recent research study investigated an international field experience for preservice teachers, labelled as a service-learning internship, a term often used to refer to a student teacher in a Bachelor of Education (BEd) program. Relying on what we know to be advantages and benefits of similar international field experiences for preservice teachers to frame our investigation, we explored the impact of a service-learning internship upon beginning teachers, particularly as it related to their professional growth as teachers. To gain insight into teacher education, we drew on the work of Mollenhauer (2014) to critically examine the foundations of how we prepare teachers in our $\mathrm{BEd}$ program. Analysis of questionnaire responses, tracked by a digital discussion forum via Moodle ${ }^{\mathrm{TM}}$, revealed two dominant themes: (a) gaining a deeper understanding of children, and (b) learning to be flexible regardless of curricular constraints. Results from this study might be of interest to those who share a similar interest in international field experiences, teacher education, and pedagogy.
\end{abstract}

Keywords: pedagogy, Bildung; teacher education; international; field experience; service learning; global teaching

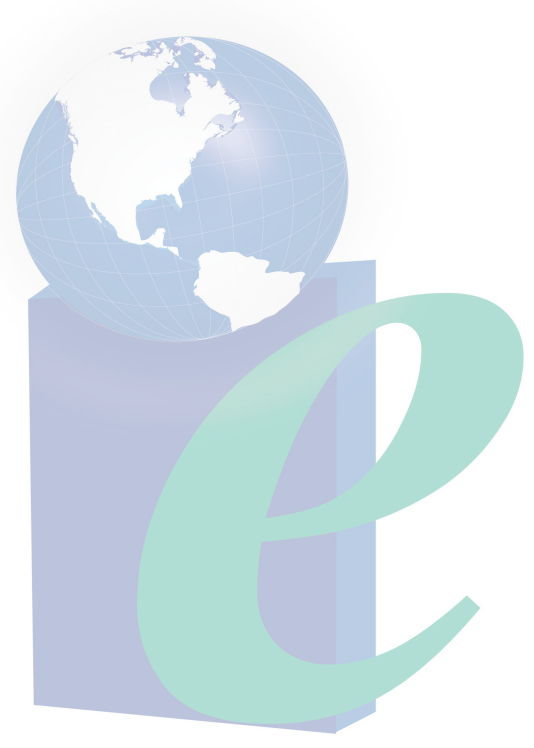




\section{Mollenhauer's Representation: The Role of Preservice Teachers in the Practices of Upbringing}

Successful completion of a field experience is a current prerequisite for teacher certification. Over the last decade, our School of Education has offered an international field experience option for our preservice teachers to experience global teaching. During this time, a number of teacher education programs in North America similarly have included international field experiences as a program extension for their preservice teachers (Robinson \& Bell, 2014; Stachowski \& Sparks, 2007). The impetus for such internationalization in teacher education programs falls into one of two categories: (a) program driven, maintaining a contemporary focus drawing on multicultural and/or global education to enrich teacher understanding or (b) financially driven, offering an international incentive to attract potential students as an advertised student recruitment tactic (Baker \& Giacchino-Baker, 2000; Pence \& Macgillivray, 2008).

Irrespective of this initial impetus, we believe international placements ought to help students contextualize the academic elements of teacher education coursework with in-field teaching. We make deliberate attempts to connect academic lessons in our teacher education program to the field through four distinct phases: initiation to the practice of teaching, teacher development, teacher expansion, and teacher consolidation. At our university, we carefully select international hosting countries to ensure the teaching placements for our students provide a learning experience beyond teacher tourism. A primary justification of international teaching placements is one of contrast. That is, we consistently endeavour to encourage our students to examine the differences between host countries' education systems and our own so that they may become able to critique the merits and shortcomings of our own education program and system.

\section{Two Dominant Themes}

Cumulative experiences teaching internationally reveal differences from country to country that are both significant and subtle. The initial findings in this article are aligned with past lessons learned from Iceland, Norway, Australia, Kenya, and this current study in Belize (see Robinson \& Bell, 2014). Here, we primarily focus on two dominant themes: (a) teaching relationships and (b) the need to embrace curricular flexibility as a preservice teacher. Our observations from over 10 years of leading international teaching experiences have confirmed that international placements can challenge the intended outcomes of a program approach as critical markers of preservice teachers' competencies and their professional readiness for the teaching field. To guide our critical examination of our teacher education program and to better understand and analyze the data for this study, we drew on Mollenhauer's (1983, 2014) work, specifically pertaining to the upbringing of children - considered a central role for teachers.

The dominant focus in preparing beginning teachers revolves around what it means to be a professional, using such tools as assessment, outcomes-based education, instructional strategies, classroom management, student behaviour, educational law, school board policies, inclusion models, and diagnostics for special education. While these topics are important in preparing preservice teachers for their roles and responsibilities with children and youth, pedagogy is another more profound reason to teach. Yet, this element is often forgotten or ignored in educational discourse and practice in Canada. In this research, pedagogy refers to the relational qualities between a teacher and children as they grow and mature (see Foran \& Saevi, 
2012; Savie, 2011 van Manen, 1991, 2015) and for Mollenhauer (2014), pedagogy refers to reflecting on these youth encounters.

\section{Mollenhauer}

Mollenhauer $(1983,2014)$ posited the primary function in teacher education programs is to question how to best prepare adults to take their place alongside children. Some programs may attempt to cover pupil growth or personhood as a stand-alone course topic in child psychology and youth maturation, yet this tends to be represented through standardized development timelines informed by human-development theories.

In discussions during their international placement application process, many preservice teachers stated they were looking for something different or felt something was missing from their Canadian teacher education experience. Our preservice teachers struggled to find words to articulate the gaps intuited, what van Manen (1999) would state as the "pathic" (sensed or felt, rather than thought), in education, the pedagogical (p. 17). Many alluded to a relational aspect and a desire to understand a more humanistic approach to counter the technical focus often foundational in teacher education. These discussions motivated us to focus critically on our ongoing review of program quality, including the international component, anchored in the following questions: Are there alternatives to our current preservice teacher orientation? Should the program be revived or redeveloped to address the challenges confronting teacher education in North America?

We believe international placements are central in helping preservice teachers develop a pedagogical practice and by making connections to Mollenhauer's $(1983,2014)$ treatise of Bildung, we can strengthen our program by what is learned from the reflections shared by our preservice teachers on their international experiences. Mollenhauer $(1983,2014)$ described Bildung, upbringing, and pedagogy as characteristics of education. The scope of these themes includes the realms of school, family, and society, inclusive of the personal and domestic and the professional and scholastic.

Teacher education in Canada and North America has largely ignored the personal and non-professional significance implied in pedagogy (Siljander, Kivelä, \& Sutinen, 2012). Mollenhauer's (2014) findings encouraged us to return to forgotten basic human connections to understand pedagogy in its challenging complexity and unspecialized simplicity. In this way, we evoke Mollenhauer's tradition of Bildung or formation - the experience of shaping ourselves, the world around us, and being shaped by others. Mollenhauer (2014) characterized Bildung simply as the "way of the self," and "helping people, above all youth, to find their Bildung" (p. xvii). Galvin and Todres (2007) rejected the specialized language of education, sociology, and psychology and instead used questions and exploration of the mutual circumstances of being human in shared cultural histories. This humanizing aspect is central to the gaps identified by our preservice teachers.

\section{Preservice Teaching Within a Developing Nation (Belize)}

Villegas and Lucas (2002) investigated the impact of international field experiences on preservice teachers, and the literature related to these experiences is seemingly unequivocal: Though preservice teachers experience both intended and unintended consequences during placements, their outcomes were markedly positive with few negative ones (Willard-Holt, 2001). 
Our investigation tested these findings in our own BEd program outcomes in preparing competent professionals for classroom practice. Drawing on preservice teacher reflections on teaching youth in Belize, removed from the North American teaching context and our predetermined $\mathrm{BEd}$ program expectations, including classroom traditions and lesson plan standards, allowed for different professional realizations. After many years observing the benefits of our undergraduate program's international field experiences in many different cultural settings, we introduced the service-learning internship to preservice teachers as a pilot course and research study within our university's BEd program.

\section{Related Literature}

Before planning and researching this service-learning internship, we reviewed literature related to the advantages and benefits of international field experiences, teacher education, pedagogy, educational internships, and service learning as an educational model. Ongoing analysis of field experiences provided an understanding of the role teacher education programs have in the development of future teachers (Adams, Bondy, \& Kuhel, 2005; Athanases \& Martin, 2006; Ronfeldt, 2012).

International field experiences. Studies specific to preservice teachers in international settings explored related changes to professional and personal identities (Pence \& Macgillivray, 2008). Pence and Macgillivray (2008) stressed the importance of reflection-on-practice. Clement and Otlaw (2002), Stachowski, Richardson, and Henderson (2003), and Quezada (2004) relied upon data from preservice teachers' reflections and found changes in their instructional approaches, self-learning, and understanding related to multiculturalism. For example, with respect to instructional strategies, preservice teachers found they had to become more creative in their planning and teaching when they lacked material resources. Additionally, preservice teachers who immersed themselves within a new community during their international field experience developed genuine understandings about others and their cultures (Quezada, 2004). Kabilan (2013), Kambutu and Nganga (2008), and Sahin (2008) noted that through international placements, preservice teachers gained an awareness and an authentic understanding and appreciation of the hosts' cultures, allowing for beneficial and meaningful professional development. Interestingly, however, the pedagogical understanding as defined by Mollenhauer (2014) or van Manen (2015) is absent from this literature.

Service learning as a learning opportunity. Developing a service-learning internship course was an effective way to create a flexible, responsive teaching arrangement that could operate outside the parameters and expectations of the typical field experience placement. A service-learning course differs in both structure and purpose from field experiences, where professors generally have little-to-no substantive involvement with their students' day-to-day teaching experiences. Within a service-learning arrangement, professors design learning outcomes, help students connect in-class learning with in-the-field experiences, and spend time with their students engaged in the community contexts (Stevens, 2008).

For Bringle and Hatcher (1995, 2009) and Stevens (2008), one of the most important aspects of service learning, particularly as it differs from field experiences, is the enterprise that benefits both the student and the community member as both parties have something to offer and to gain. According to Simons and Cleary (2006), university students noted several positive outcomes related to service learning, including personal progress, community self-efficacy, and 
social development. Similarly, Baldwin, Buchanan, and Rudisill (2007) found that preservice teachers who engaged in a service-learning opportunity cultivated a deeper understanding of diversity and social justice and, thus, more readily recognized these aspects within their own communities. Service learning was significant for our participants as a means of entering the teaching realities of Belize. They developed an understanding of the culture, the people, the place, and the uniqueness of context while challenging their own assumptions of global awareness; this process also revealed the limitations of their BEd program.

Relatedly, and recognizing traditional (and local) field experiences' failure to offer preservice teachers opportunities to engage with students from diverse student backgrounds, McDonald et al. (2011) have also suggested value might be found in placing preservice teachers in community-based organizations (CBOs) outside of "normal" school contexts. Among other goals and benefits of such placements, McDonald et al. found that preservice teachers become better able to develop more holistic views of children and youth and that they also might come to see that students (and their neighbourhoods or communities) ought to be placed at the center of learning.

Place-based education. In accordance with Mannion and Lynch (2016), place has a primary role in our service-learning internship due to the natural, informal, outdoor, teaching spaces our preservice teachers use to engage their students. Other researchers (Lewicki, 1998; Leo-Nyquist \& Theobald, 1997) have also made similar claims, arguing pedagogy of place formalized teaching to include rural and natural settings in educational practice. The understanding of place resulted in a deeper community awareness, and this connection to the relevancy of curriculum was just as critical in what and how a student learns. Unlike the traditional North American standard, our participants engaged youth in fields, treed areas, riverbanks, jungle paths, and in their host village itself as everyday sites for teaching. This pedagogy of place connected the school to the surrounding outside world. Although Sobel (2004) added that placed-based education restores essential links between person and place, and Knapp (2012) highlighted that North American schools today tend to separate from the community in which they operate, teachers' relationships with their students outside formal sites of instruction have not been fully explored pedagogically.

Other scholars (Foran, Stewart Stanec, \& Mwebi, 2009; Gill, 2010; Hubball \& Kennedy, 2009; Mygind, 2007) articulated the importance place has in an individual's learning, and stated place is essential to quality learning experiences. These studies did not focus on pedagogy as a relational experience between teachers and children, but centred on the value of learning outdoors and accented similar findings in the need for natural places (see Foran, 2005, 2008) that support relational practices. The literature supports the benefits of a non-traditional educational setting and the relational connections between the teacher and student-especially the casual unfolding of relational awareness (Davidson, 2001). Nevertheless, these studies fall short in adequately exploring the relational whereas Foran's (2008) research indicated pedagogical dimensions were possible in outdoor settings.

Other research (Allen-Craig \& Schade, 2013; Louv, 2005, 2012; Selhub \& Logan, 2012; Zelenski \& Nisbet, 2014) substantiated the importance of natural places in our daily lives, but challenged our propensity for overreliance of urban-dominated structures and indoor spaces as solely places for learning. We argue the natural world is also a place in which to base teaching and learning, and this should be central to how we prepare teachers to assume their professional 
responsibilities. Place-based education should not be an alternative pedagogical orientation for learning to teach youth. The immediate challenge for place-based practices in education is for teachers to operate outside a school-centric curriculum that ignores the pedagogical significance of experience in favour of academic results. Thus, to draw on Mollenhauer (2014), a forgotten connection resides in what we consider to be places where we encounter young people and the purpose of our actions with them.

Bildung. In contemporary educational discourse, there is increasing emphasis on universal curricula and testing for metric comparisons and ranking purposes. Thus, local culture (or place-based education) is not measured or valued as important in efforts to homogenize youths in becoming global citizens - a counter aim to Bildung (Mollenhauer, 2014). Culture is usually marginal from classroom operations and not necessarily tied to the curricular expectations, falling under teacher direction only in indirect experiential opportunities. Teacher educators recognize that teaching is a complex humanistic engagement and is more than delivering the prescribed curriculum. Associated with education are many intangibles such as confidence, resilience, responsibility, enjoyment, engagement with others, learning culturally, discovering promise of self, and extending of self as a growing person in the world where youth find themselves to be (Friesen \& Saevi, 2010) via the guidance of a caring adult. These intangibles, pedagogically guided, align with Mollenhauer's (2014) reconnecting to Bildung. Therefore, culture should be maintained and enriched through education, a passing down of culture as a means of shaping one's world.

Our participants said cultural awareness was significant in their ability to connect to youth and to the place where they were teaching. Culture was central to their understanding of teaching in Belize, and place had a direct impact on their growth as educators. Foran (2005, 2008, Foran, Stewart Stanec, \& Mwebi, 2009), along with Foran and Saevi (2012), and Foran and Olson (2008) found that place is central as a medium in developing the relational capacities between adults and children, the teachers and students. A less institutional and more informal place allows for pedagogy, where the relationship naturally emerges between the teacher and student, replacing the artificial confinement of institutions. van Manen $(1991,2015)$ and other European pedagogues and educational theorists (e.g., Biesta, 2011; Friesen \& Saevi, 2010) noted this relation is often dismissed or taken-for-granted in teacher education.

Biesta (2011) claimed that while Anglo-American educational studies are "based on a particular object of study," education in Germany, Pädagogik, "is based on a particular valueladen interest" (p. 188). This interest is profoundly normative in an ethical sense and focuses on the interests of the child and on the future possibilities of society in general. Their claim is central to the meaning of pedagogy (Foran \& Saevi, 2012; van Manen, 2015) because the relationship between adult and child forms the interpretive frame for understanding various educational practices. Northern European pedagogical tradition considers human relationality between younger and older generations as indispensable - and pedagogy as an unavoidable part of inter-generational interaction. Mollenhauer (2014) emphasized that the continuation of human existence is centred on the relation between adults and children. Because of its orientation to an open future, this relationship does not exist for the sake of the adult, but for the benefit of the child.

An outcomes-based and assessment-driven education is not oriented to an open future for the child; rather, it forecloses on multiple possibilities by insisting on pre-established criteria, 
percentiles, and performance norms. Friesen and Saevi (2010), interpreting Mollenhauer's (2014) work determined, "the pedagogical relation can be described...situationally and ethically normative, rather than developmentally and socially normative" (p. 140). To this is often added a biological conception of cognitive performance and deficits, tempting some to reduce the child to a diagnosis or a dysfunction or to a ranked score indicating academic success. In this context, both the teacher's and the child's humanity are jeopardized. Mollenhauer states such humanity and attendant pedagogical priorities should be given precedence over social and psychological norms and outcomes. This belief articulates the gaps identified by our preservice teachers. Their task is an educational practice of Bildung or self-education, of crossing the divides in society of the personal-domestic, private to the institutional, professional-public, and cultural spheres. This is deeply intertwined with the human cultural understanding, language, action, morality, and relationality at the base of pedagogical practice.

\section{The Study}

Five of our full-time, Year 1 BEd preservice teachers enrolled in the three-credit, servicelearning internship within Belize, a developing nation. They drew on best practices they have learned to date, in a teaching arrangement that was a departure from a typical field experience offered in our BEd program. In addition to pre-departure and post-return activities and assignments, students were required to lead a two-week summer school program within a small rural community. These assignments included detailed lesson plans, pre-departure and postreturn journal responses, and a final reflective paper. One faculty member organized the course, supervised the internship, and graded all the assignments.

With scant appropriate instructional material resources available, they designed and delivered several modules related to contemporary curriculum and other curricular outcomes related to, for example, physical education, music, science, language arts, and art. Teaching space was limited primarily to an outdoor field, as well as to a lone sheltered area in case of rain or extreme heat.

\section{Research Question(s)}

The primary research question framing this study was "In what ways did the informal international teaching placement inform your teaching and contribute to your growth as a teacher?" In addition, questions posted in Moodle ${ }^{\mathrm{TM}}$ were related to preservice teachers' preconceptions going into Belize; these responses contrasted with their in-field observations and reflections from their teaching experiences during their service-learning internship.

\section{Research Methods}

The research design was a multi-case study; however, the results within this paper are related to only one bounded case. The bounded system (Creswell, 2003) was one group of five preservice teachers $(n=5)$ who participated in an international service-learning internship in Belize. It is also important to note that one of the two authors (Daniel Robinson) was present during the entire internship. Though he was not a focus of the study, his presence, nonetheless, must be acknowledged herein. In this sense, Daniel was a participant-observer whose own biases would have (unapologetically) shaped both the experience of the preservice teachers as well as his interpretations of their accounts. Moreover, the other author (Andrew Foran) has been present at a number of other international internships and so though he was not an "active" participant- 
observer in Belize, his own experiences with similar initiatives would have shaped his interpretations of the preservice teachers' accounts.

Data were collected using questionnaires administered to all participants just prior to the service-learning internship and immediately after the service-learning internship ended. The prequestionnaire had seven questions and the post questionnaire had 12 questions. Each question asked for a 300- to 500-word response, and we estimated each questionnaire would take 60 to 90 minutes to complete. Respondents had two weeks to complete each questionnaire. Sample questions included:

- What are your preconceptions before going to Belize related to the students? (pre)

- What do you think you will learn professionally? (pre)

- What were your observations when you arrived in Belize related to your anticipated strengths in the new context? (post)

- How might your future teaching be influenced by your participation in this international experience? (post)

\section{Participants}

Participants ranged in age from 23 to 26. They had a full academic year in the BEd program and two prior field experiences teaching in Nova Scotia schools. All have since graduated. Four participants self-identified as female and one self-identified as male. All participants had a specialization in physical education, with other subject specializations in science, social studies, language arts, or math. Their teaching streams covered elementary, middle school, and high school grades.

\section{Research Ethics}

The University's Research Ethics Board approved all research protocols, including those related to dissemination guidelines. We endeavoured to follow all these protocols and recused ourselves when any potential issues arose (e.g., when a participant was also a student in another class taught by one of the researchers). To protect the confidentiality and anonymity of all participants, pseudonyms are used throughout the rest of this text.

\section{Data Analysis}

We analyzed all data by searching for issues, similarities, differences, recurring ideas, clustering, patterns, and relationships in the responses. By coding and categorizing the data according to methods outlined by Creswell (2012) and Miles and Huberman (1994), dominant themes emerged, allowing for analysis and interpretation. Analysis of questionnaire responses resulted in two dominant themes related to the growth of the teacher: (a) teaching relationships, and (b) the need to embrace curricular flexibility as a preservice teacher.

Drawing on Mollenhauer's (2014) work to analyze participants' reflections, we concluded personal growth formed the base of their professional growth in concert with our program. Participants came to a better understanding of Self, as a person, adapting to Belize's way of life. Significant in this realization was the value they placed on immersing themselves in another culture and letting go of the formality associated with teaching. These individual elements are particularly relevant to Bildung, and the data analysis focused on the theme 
"Growth of the Teacher" to explicate lessons to advance our own teacher education practices to better lead preservice teachers in future international placements.

\section{Growth of the Teacher}

Aoki (1984) stated that reflection-on-practice is not limited to instructional techniques for lesson plan enhancements but includes the moments we share with children. van Manen (1991) continued this thinking by linking pedagogical reflection to practice that enables teachers to know what is wanted for children. This is a special way to reflect and is a demonstration of a pedagogical attitude that presents significant moments for a growing child. van Manen's (1991, 2015) work showed an educational dimension that reveals a need for teachers to be in attunement with pupils in a mutual relationship, and attunement is realized only by being with others, being in their presence fully (Heidegger, 2001). For van Manen (1991), this is a tactful expectation for teachers, to be fully there for their pupils. Attunement in practice (Aoki, 2005, p. 165) is a teacher's way of being present for children and is the base for educational reflection.

Attunement, if pedagogically positioned, reveals deeper teacher understandings of the relational bond with students that has become de-emphasized in current teacher education programs in favour of more technical-, cognitive-, or behavioural-driven educational models. The current topics in teacher education anchoring the preparations of preservice teachers crowd out pedagogical practices (van Manen, 2015) and reflect a preoccupation with numerous teaching competencies that take priority over relational dialogue and reflection, specifically concerning the teacher-student relationship or the growth of the child becoming a person. Mollenhauer (2014) reminded readers of a relational practice that helps people "find the path of their Bildung" (p. 13), the shaping and developing of self and the role education has in this process of self-formation (p. 13); this challenges North American educational practices, declaring "pedagogical norms have priority" (p. 17). We argue international placements are opportunities to contrast our efforts in teacher education and ask if our practices need to be revived or redeveloped to answer the challenges confronting education in North America (Aoki, 1984).

Mollenhauer (2014) implored that we should start anew to understand what education is actually about, to allow us to see education as a means of Bildung, beyond theorizing education. Our service-learning internship was a deliberate attempt to move in this direction and challenge the mind-set of the field experience as the site to learn about teaching. Mollenhauer addressed a pedagogical-existential issue poignant for teachers' reflective capacity, demanding that we, as adults, question the significance of our relationships with our youth because we are responsible for the upbringing and education of them; we ought to ask, "What should my part be in this young person's path to the future" (p. 53)?

With this in mind, we analyzed the data, drawing on two of Mollenhauer's (2014) pedagogical orientations: (a) Representation - selecting what to convey, and (b) Presentationsharing something about one's self and ways of life. Our effort reconnects practice (Aoki, 1984) to pedagogical reflections in preservice teacher education. Presenting the accounts of preservice teachers' views based on their Belize experiences deepen these pedagogical reflections beyond a curriculum of "mere appearances" (Mollenhauer, p. 167) and embraces Aoki's view that a teacher's practice needs to surpass mere technical considerations of instruction. We reveal how 
beginning teachers, in their pedagogical reflections, naturally tend to value the practice of upbringing, Bildung, over the diagnostic-scientific representation in teacher education.

\section{Theme 1: Teaching Relationships}

A dominant thread in participants' reflections was relationality-the importance and value of being able to connect to youth. Our preservice teachers realized early in their careers that this humanistic connection was essential beyond the technical aspects of planning, preparing, and the rudiments of delivering a lesson plan. Embedded within many of their reflections was the realization that youth in Belize were the same as their Canadian counterparts, and that all global cultures shared the experience of raising children. As Jenn explained:

Teaching...highlighted...that no matter their social economic background, their religion, their level of schooling or their nationality, children are still children, and still have those same principal, kid-like characteristics. ...There were students all over the spectrum of enthusiasm for activities. ...For every troublemaker there was a well-behaved kid and for every shy kid there was a rowdy kid; the...behaviours we witnessed were very similar to what you would find in a Canadian classroom. ${ }^{1}$

Not only did Jenn draw parallels between youth in different countries, but she also realized that her bond with students was as important as her delivery of the lesson.

I got to know the kids very well within just the 2 weeks; ...I created stronger bonds with these kids than I did with the students I taught for several weeks in practicum [in Canada]. It may have been due to the different circumstances, but it showed me how important those bonds are for myself and for the students.

Olivia observed that central to the engagement was the informality of the environment. The place allowed relationships to form, and her observation resonated with others and us. For example, during the first few days in Belize, they realized just being with the children and youth, on their terms in this place, became a benefit through which they learned more about their lives. Olivia noted:

My favourite part of the day was the walk to the river. ... Some of the best conversations and sing-alongs were had on that walk, and it was a time where I really got to learn who they were outside of the "classroom." This part of the day reminded me of how important it is to get to know your students - not only as learners, but also as people. Yes, we were in a foreign country and working with kids from all different cultural backgrounds, but kids are still kids. ...My experience...reminded me of how important it is to build positive relationships with your students and how rewarding it is to be involved with their development as people.

Rebecca, like others, observed that the children in Belize were similar to children in a Canadian classroom:

Just like Canadian children, they had the activities that they liked and those that they disliked [and]...they were not always willing to participate. ... Regardless of culture and background children all over the world have a lot in common. They all want to be accepted as they are and have encouragement, validation, and a level of fun while learning. 
Likewise, James observed similarities between children in Belize and Canada and that the classroom was secondary to the relationship:

You do not need fancy schools or modern facilities to host a good environment; you just need to provide a safe and fun learning environment... [to] maximize their potential. We provided a consistent environment where we would be at the same place same time and had organized activities for the students to partake in everyday. [We] created an environment where the students felt like they could trust us and feel safe to have fun and give it their all. We did not need up-to-date technology or contemporary equipment to gain the students' trust and attention; all we had to do was show up and provide a positive environment for them each day. I think that consistency with learning environments instills confidence in students, and confidence is the prerequisite for success. Students love to learn, and they love to feel a part of a community. As long as I can make the students feel important and special and that they belong, learning and teaching is the most enjoyable thing someone can do in life.

While all participants seemed to recognize that the youth in Belize were in many ways similar to those in their prior Canadian teaching placements, they discovered the central element to the success in this field placement was being able to relate to the youth.

The realization that a suitable learning environment can emerge from things other than instructional dominance was a welcome one. We were hopeful that, upon returning home, these teachers would resist the temptations to focus only on the scholastic elements instead of on students who deserve their attention and guidance. These reflections begin to address one of Mollenhauer's (2014) fundamental questions of why we even want to be with children. The question eclipses the content-subject specific focus, and has potential to shift a teacher's reflections to not only consider what is being presented, [but]beyond the content dominant lesson plan, to what Mollenhauer would refer to as Representation by asking: What does this mean for children?

Drawing on 18th century educator Pestalozzi, Mollenhauer (2014) raised a fundamental question for adults to consider: "How should we represent to children what it means to live a good life?" (p. 52). This is counter to the teaching standard of what curricular outcomes a subject area should represent and how to measure the knowledge, skills, and attributes of the lesson. Mollenhauer (2014) explained Pestalozzi's contribution to pedagogical practice during the French Revolution in the context of a fractured and fragmented world, a world of absentee parents and economic and political upheavals:

When the circumstances of everyday life no longer have any inherent pedagogical significance, then the basis for responsible upbringing had to be found in the minutest but indispensable moments of all pedagogical relationships between teacher and student. This relationship...is concerned with concrete social arrangements-with a "household." (p. 52)

The relationship between adult and child in this context is institutionally mediated; the adult acts in a professional capacity and based on rules, guidelines, and codes of conduct. Yet, the child does not seek a relationship on these terms, nor may even be aware of them. Consequently, the 
adult needs to be "concerned with concrete social arrangements... a place of safety and security for the child" (Mollenhauer, 2014, p. 52). This realization is in concert with participants' reflections. The circumstances they experienced can be determined as providing "a higher basis" for educational activity (Mollenhauer, 2014, p. 52), one that is not to be understood simply in instructional terms. Mollenhauer (2014) explained this higher basis in terms that are emphatically non-instrumental, as "a moral and personal relationship between the adult and the child" (p. 52). Moving beyond institutional practice, participants found a way to relate to children in Belize that was not just academic, via lesson plans or prepared activities for the day. Preservice teachers' reflections on informal engagements can help teacher educators realize that they, and the children too, truly value the teacher-pupil relationship.

Comparing the complexity of our current global state, Mollenhauer (2014) pointed out that in the chaos of the Napoleonic wars, Pestalozzi could no longer simply rely on the power of representation typically found in established curricula, generalized content, and mostly abstract over-simplified topics in the hopes that classroom practices would help youth make connections. Pestalozzi's account is articulated not in terms of abstract theory and principles of learning, but as a poignant need for relationality. Like Pestalozzi, James worked to form a relationship with his students in a "safe" domestic world.

Despite schooling's formal aim to serve students, education was not structured based on how young people see or want to be in the world, but rather was regulated to reflect an adult version of the world via the official curriculum. Participants recognized this struggle to be morally and professionally a part of this educative world and acknowledged children's need to belong. Like Pestalozzi, Mollenhauer (2014) noted these two spheres were not always in sync, and desired to cultivate a place where children could grow and "to make the institution a crucible" (p. 50). Both desired to "restore in the children a sense of what was right, decent and moral" (Mollenhauer, p. 50), pedagogically seeing that being a child was a greater need not always served in the lesson plan.

\section{Theme 2: Embracing Curricular Flexibility as a Preservice Teacher}

Mollenhauer (2014) pointed to Amos Comenius's Orbis Pictus to illustrate the complexity of education and culture in a world of increasing specialization, trade, and heterogeneity of that time period. According to Mollenhauer (2014), Comenius's guiding principle for developing curriculum was that "each fact or phenomenon should be represented to the child in such a way that its meaning within the overall scheme of things and life itself is clear" (p. 37). Although this overall impression of life itself was presented as textual and pictorial, and somewhat abstract, it still represented a part of the world. Yet, such representations of the world are selective, partial, and even distorted. When it is based on what is being represented indirectly to students through books, pictures, and text, the pedagogical experience and relationship between adult and child becomes tenuous.

In North American education, we have mistakenly relied on the abstract, and ultimately artificial, impression over the reality of immediate experience and relationships. In doing so, we place our educative hopes in structures and measures to define our relationships with children and, as a result, curriculum documents, academic scores, and classroom management become the reasons or educative focus for why we teach. Jenn described a clear realization of this curricular challenge: 
We have to be able to think on our feet, be ready to adapt to the best of our ability and get to know our students. ...We [had to] alter activities throughout the two weeks... whether it [was] due to the weather, the student's interest level, or accessibility, it was integral to the program to be able to think on our feet and to be open to changing plans. It taught me that when things do not go to plan, it doesn't necessarily mean the lesson is ruined.

Jenn found it difficult to only live the plan, and realized the necessity of letting go of the curriculum. She rejected the curricular imperatives imposed by the pressures of the established lesson plans of teacher education. When it seems to have little or no value to the lives of children, adults must recognize the need to adapt.

In Belize, scant digital or material resources were available for planning and/or teaching; consequently, participants created engaging educational environments with words and actions rather than with books, technology, and equipment. Rebecca captured the realities of curricular limits:

We realized...we would have to [further] adapt our lesson for the location and group of children. ... I learned that we don't need all the bells and whistles to ensure the quality of the lesson. While it is important to take into account the physical environment, I learned that while there may be cultural differences that all children crave the same things in an educational setting. They like to achieve, but most importantly they are looking for acceptance and a safe, yet fun learning experience. ...Just by listening to the students speaking to us and [to] one another, there is so much that can be learned about them and their lives. By teaching them I could see that you can learn a lot about their culture and how they interact with one another.

It quickly became evident to participants how often their teaching in Canada included "bells and whistles"; they had elevated the planning stage as an all-consuming affair-typical for beginning teachers.

Rebecca's reflection resonates with Mollenhauer's (2014) curricular intent to seek the human connection as primary. Her comments echo Mollenhauer's pedagogical efforts in creating a place for children, to give them a space to become good people under the guidance of moral adults. Rebecca realized that a curriculum guide or lesson plan does not tell teachers how to be with young people. When the lesson plan does not measure up to the needs of the youth being served, the adult must recognize that the representation (curriculum), and the supposed learning (conveyance) or purpose, needs to be abandoned in favour of what will serve children best (the pedagogical) in becoming a person.

Furthering the discussion on curricular reliance and dominance in school life, James expressed the means of representation and instruction as secondary to knowing the students:

I feel like we got away from our lesson plans as we got to know the students better. I think this is a valuable lesson to learn regarding planning and preparation. ... [When] we started to get to know our students well enough to loosely follow the lesson plan and do other activities that were better catered to the group, the better our sessions went. I think the biggest thing I took away was [to] have a plan in place and be prepared but also know what works best with the group of students. 
As advisors, we too expected adherence to the lesson plan standard, continuing the BEd program expectations, regardless of the new and unique teaching and learning context within Belize. Participants were required to first submit and refine detailed lesson plans - activities first seen as useful by all preservice teachers, who commented that it was essential to "over" plan.

But, according to Jenn, the number of unexpected contextual variables related to their environment, the plan was in constant flux, and expectations were modified to plan "as a guide," meeting the "people and the place." Jenn shared a glimpse of the formal-informal learning environment:

Some of the plans just did not work with the people and not in the place we were teaching. We think that the kids in Belize picked up skills quicker and easier than certain kids in Canada because of how much time they free play and explore how their body works. ...During those walks [to the river] I learned about their families, what they liked to do in their spare time, what their life in Belize was like and it was also where we could share more about our lives in Canada with them as well. ...At first it was a little daunting as I felt weird for our sessions to be way less structured than...but I loved that. It gave the kids a chance to just play and swim around. Some kids wanted to learn how to be better swimmers,... some kids just wanted to play fetch with the sinking rings, some kids just wanted to hunt shrimps; in the end, every kid left happy.

Likewise, Kelly observed:

When you are going into a situation almost completely blind like we did in Belize, you have to be able to adapt and go with the flow. Preparing our units ahead of time allowed us to have something to base our lessons on, even if what we had planned isn't exactly what we ended up doing. However, having that bit of unknown was good because of how it forced us to adjust to the environment. As a teacher you need to be able to handle everything that comes at you and just gaining experience in this unfamiliar context will be beneficial to my future teaching.

Although Kelly was forced to spend considerable time re-planning, she suggested that this experience will have a positive impact on her own future teaching. She learned that she could let go of the curricular guides, loosen up planning, and be more creative. Kelly's experience of learning to be flexible stimulated her critical reflection on planning practices and what it means to spend time with children. This experience disrupted the dogma that forces teachers to adhere to detailed, perhaps overly prescriptive planning efforts, often criticized by beginning teachers as extreme, daunting, and unrealistic.

Participants came to learn that the value in a good plan is a degree of latitude and flexibility; this realization is most affirming for us. Olivia revealed this value of flexibility:

[We] created thorough lesson plans that included instructional cues and questions that would guide our teaching [and] the right materials and equipment to run our lesson. But everyday brought in a different number and grouping of kids, so we constantly had to make adjustments to accommodate these changes. Some of the activities that we planned for went faster than expected [and] Steve and I would strike up a new game or activity to keep the lesson going. ... These filler activities worked really well and helped keep the kids involved and interested. 
Echoing Olivia, Rebecca captured the experience of the unexpected:

While changes in resources and physical facilities often can affect the way that you are able to deliver your intended lesson plan I learned that a true professional has to have the ability to be flexible and that you must constantly evaluate your effectiveness as a teacher and be prepared to change your approach on the fly to be successful.

As if responding to the need for teacher flexibility and youth freedom, Mollenhauer (2014) framed the paradoxes posed by academic achievement, on the one hand, and motivation or, rather, the child's vitality on the other.

In a world that values achievement and reliable results above all else, how can we foster an attitude that is about enlivening? How can we do this - especially if it may produce results that jeopardize predefined educational outcomes? Referencing Pestalozzi again, Mollenhauer (2014) expanded on this conflict, where because of "the circumstances under which people live...[teachers] have lost their power to educate the young and can no longer reliably represent in a way that is helpful for their Bildung" (p. 46). However, in the absence of educational force, the demise of educational power, influence, and social position (Biesta, 2011, 2012), Mollenhauer (2014) contended that a special "realm of Bildung must be 'created' for the younger generation" (p. 46), one that is "designed in such a way that it reliably reflects reality rather than just surface appearances" (p. 46). Similarly, our participants struggled to follow the prescribed curriculum, only to acquiesce to the place and the child exploring their natural world.

\section{Learned Lessons for Future International Placements}

The predominant curricular reality in North America is one of restriction, instructionally not designed to help a young person find one's Self-Bildung. Thus the unique setting in Belize allowed for an informality to allow adults (teachers), children, and young people to co-exist on terms away from institutional constraints and teaching expectations (Davidson, 2001; Foran \& Olson, 2008; Knapp, 2012; Lewicki, 1998; Mannion \& Lynch, 2016; Leo-Nyquist \& Theobald, 1997; Sobel, 2004). Mollenhauer (2014) explained that in this situation, we are confronted with three fundamental problems when it comes to upbringing and educational representation: "1) Of all the things there are to learn, which ones are truly important; 2) How can these be conveyed with the needed clarity; and 3) How can children be motivated to take on the material represented to them" (p. 46). Jenn offered insight as a starting point in addressing these questions for preservice teachers:

We are still learning how to be teachers; we are constantly being evaluated by our CTs or Faculty Advisors. During my practicum I often put the pressure on myself to follow the plan directly and I've found myself worrying more about little things such as running out of time, having too much time, or an activity going wrong than actually focusing on my student. ...I've learned...sometimes, no matter how much you plan and prepare things will still go wrong and the most important part is to be okay with that. I think it is a good idea to put effort into planning and preparation, but just like in Belize, there will be times when I will not know what to expect, my class and my plans will have to change. This experience is quite different than when we were in the classroom, as it is very informal and chill and I think we developed a different sort of relationship with the kids than we would in a school. The camp-like nature of the lessons really facilitated growth... although not everyone may think those areas are "professional responsibilities." 
Mollenhauer (2014) isolated and connected key words that are essential in understanding the pedagogy: "relationship," "moral way of life," "stimulat[ion of] their inner lives," "atmosphere," and "harmonious perceptiveness and activity" (p. 51) as teachers guide youth.

This setting does not impinge upon children's needs or violate their sense of self worth ... enables children to engage in moral behavior without coercing them...brings to life the productive energies and the spiritual and intellectual potential of the child...[and] makes all of the above possible through social arrangements...serv[ing] as a model way of life. (Mollenhauer, 2014, p. 52)

Mollenhauer (2014), working with Pestalozzi's "way of life" (p. 51), reveals its structural interconnections and influences that position the relational need first in being with youth. Some may argue that this way of life, as a working model for moral education, is difficult to realize in our contemporary school-based practices. When this way of life model was presented to Kelly she pointed out that these "elements of what schools should be promoting are really absent under the guise of rules, procedure, and order." Jenn clearly echoed the need to rethink the overall approach and culture of schools in the light of Mollenhauer's pedagogical connection:

My teaching was similar to a lecture; I would go home and memorize facts about protists and just talk at my students instead of talking to them. Belize helped solidify how I want to be a teacher: I was not too concerned about the lessons; I was more interested in talking [to] and getting to know the kids. After getting to know them, I found the lessons flowed smoothly. ... Getting too caught up in what the professors evaluating me thought of my teaching resulted in me missing a step in the teaching process-one that I know feel is the most important - and that is getting to know your students.

Like Pestalozzi's and Mollenhauer's own explanations, participants' responses point to the aporia of pedagogical practice. They came to understanding the ethical responsibility of the older generation to the younger one, and the acknowledgment that every educational act and curricular representation is subtended by tensions and uncertainty.

Extending our learning from Comenius (Mollenhauer, 2014), we must consider curriculum that is a simplified representation of our complex world, even knowing that our subject or context curricula are selective, partial, abstract, and even distorted. Lessons that are flexible, responsive to children, and emergent in place and culture offer a pedagogical framework rather than a scored checklist of outcomes. Reliance on such a curricular artifice is itself always in tension with the desire for authentic and immediate experiences of the world. Teachers ought to recognize the child's place, a place not dependent on institutional structures, curricular imperatives, or professional instructional mandates.

Though teaching is most often regarded as a solitary profession, the service-learning internship purposely required participants, a blend of experienced in-service teachers with preservice teachers, to plan and teach together. Although we could have designed a program in which individuals taught all classes, we correctly presupposed that, given the new and unique context, participants would benefit being with children and youth informally.

\section{Concluding Comments}

An international field experience can be viewed as an occasion for preservice teachers and teacher educators to critically examine their personal-professional learning and program values. 
Though we did not also research the impact upon the approximately 75 Belizean children who attended the summer school (many who, at their own expense, voluntarily travelled over an hour to attend), our daily observations indicated participants were having an immediate and positive influence. Youth were engaged, many arrived very early, and many others had to be shooed home. Indeed, it was constantly reaffirming to see the obvious joy and excitement on the students' faces. It seemed that they wanted the days (and weeks) to never end-and our preservice teachers seemed to feel the same way, too.

Our research has shown that through their participation in this service-learning internship, our own preservice teachers benefited, likely to a greater degree than the youth they taught. With their shared teacher growth and their "life-changing" personal growth, participants were clearly engaged in a symbiotic experience where both benefitted from engaging pedagogically. Participants desired to experience something that would challenge their position as adults in the lives of children. Learning something from their service-learning internship required pedagogical reflections.

As teacher educators, we too have some degree of educational discovery that can be used to call into question what we think we value as part of our institutional BEd program. While we would like to think we could teach and nurture the kind of professional growth they experienced abroad here at home in Canada, we believe that only this very experience was capable of enabling the personal growth suggested by participants. We could not have planned for it and we could not have delivered it as a planned curricular outcome. Without question, this service learning field experience was unique and challenging, as was drawing on Mollenhauer (2014) to analyze teacher reflections pedagogically. Given the results of this research, we are hopeful that our institution and others might offer similar opportunities to preservice teachers in the future.

\section{An Addendum}

The preservice teachers who participated in this service-learning internship had an opportunity to contextualize their experience in Belize by way of completing a capping reflective paper. This assignment allowed the preservice teachers to draw upon their earlier completed reflective responses - so that they could make some sense of how the Belize experience might impact them as soon-to-be teachers at home in Canada. Though the assignment was worthwhile in some (familiar) ways, it also was an ending conversation. That is, preservice teachers submitted this final assignment and any further engagement with the content was limited to one professor's assessment comments.

To improve upon this, our next service-learning internship in Belize (that occurred in the following summer, with a new group of participants) had a different final assignment. This new task had participants complete a dissemination exercise. Participants' assignments included local newspaper articles, whole-school assembly presentations, graduate student seminars, and teachers' professional development presentations. These dissemination exercises have allowed subsequent participants the opportunity to: 1) reflect more deeply and purposefully upon how the Belize experience has impacted their own personal and professional identities and practices, and 2) engage with large and broad audiences in these reflection efforts. This has been a superior final task.

Endnote 
${ }^{1}$ Participants' responses are included here verbatim. Errors in grammar, punctuation, and/or spelling are the participants' errors and are not identified within the text (with, for example, $[$ sic $]$ ). 


\section{References}

Adams, A., Bondy, E., \& Kuhel, K. (2005). Preservice teacher learning in an unfamiliar setting. Teacher Education Quarterly, 32(2), 41-62.

Allen-Craig, S., \& Schade, D. (2013, November). Do outdoor education programs have a role to play in introducing and connecting Australian students to the natural environment? Paper presented at the Sixth International Outdoor Education Research Conference, Dunedin, New Zealand. Retrieved from http://www.otago.ac.nz/prodcons/groups/public/@outdooreducation/documents/contribut orpdf/otago075564.pdf

Aoki, T. (1984). Competence in teaching as instrumental and practical action: A critical analysis. In E. Short (Ed.), Competence: Inquiries into its meaning and acquisition in educational settings (pp. 71-79). Landham, MD: University Press of America.

Aoki, T. (2005). Teaching as indwelling between two curriculum worlds (1986/1991). In W. Pinar \& R. Irwin (Eds.), Curriculum in a new key: The collected works of Ted. T. Aoki (pp. 159-166). Mahwah, NJ: Lawrence Erlbaum Associates.

Athanases, S. Z., \& Martin, K. J. (2006). Learning to advocate for educational equity in a teacher credential program.Teaching and Teacher Education: An International Journal of Research and Studies, 22(6), 627-646.

Baker, F. J., \& Giacchino-Baker, R. (2000). Building an international student teaching program: A California/Mexico experience. Retrieved from https://eric.ed.gov/?id=ED449143

Baldwin, S. C., Buchanan, A. M., \& Rudisill, M. E. (2007). What teacher candidates learned about diversity, social justice, and themselves from service-learning experiences. Journal of Teacher Education, 58(4), 315-327.

Biesta, G. J. J. (2011). Disciplines and theory in the academic study of education: A comparative analysis of the Anglo-American and Continental construction of the field. Pedagogy, Culture and Society, 19(2), 175-192.

Biesta, G. J. J. (2012). Giving teaching back to education: Responding to the disappearance of the teacher. Phenomenology \& Practice, 6(2), 35-49.

Bringle, R. G., \& Hatcher, J. A. (1995). A service learning curriculum for faculty. Michigan Journal of Community Service-Learning, 2(1), 112-122.

Bringle, R. G., \& Hatcher, J. A. (2009). Innovative practices in service-learning and curricular engagement. New Directions for Higher Education, 147, 37-46.

Clement, C. M., \& Otlaw, E. M. (2002). Student teaching abroad: Learning about teaching, culture, and self. Kappa Delta Pi Record, 38(4), 180-183.

Creswell, J. W. (2003). Research design: Qualitative, quantitative, and mixed methods approaches (2nd ed.). Thousand Oaks, CA: Sage. 
Creswell, J. W. (2012). Educational research: Planning, conducting, and evaluating quantitative and qualitative research. Boston, MA: Pearson Education.

Davidson, L. (2001). Qualitative research and making meaning from adventure: A case study of boys' experiences of outdoor education at school. Journal of AdventureEducation and Outdoor Learning, 1(2), 11-20.

Foran, A. (2005). The experience of pedagogical intensity in outdoor education. Journal of Experiential Education, 28(2), 147-163.

Foran, A. (2008, Fall). An outside place for social studies, Canadian Social Studies, 41(1).

Foran, A., \& Olson, M. (2008). Seeking pedagogical places. Phenomenology \& Practice, 2(1) 24-48.

Foran, A., \& Saevi, T. (2012). Seeing pedagogically, telling phenomenologically: Addressing the profound complexity of education, Phenomenology \& Practice, 6(2), 50-64.

Foran, A., Stewart Stanec, A., \& Mwebi, B. M. (2009). Active outdoor living: Lets get out of the gym! The Journal CAHPERD (Canadian Association Health, Physical Education, Recreation, and Dance), 75(1), 6-11.

Friesen, N., \& Saevi, T. (2010). Reviving forgotten connections in North American teacher education: Klaus Mollenhauer and the pedagogical relation. Journal of Curriculum Studies, 42(1), 123-147.

Galvin, K., \& Todres, L. (2007). The creativity of 'unspecialization:' A contemplative direction for integrative scholarly practice. Phenomenology \& Practice, 1(1), 31-46.

Gill, T. (2010). Nothing ventured... Balancing risks and benefits in the outdoors. Nottingham, UK: English Outdoor Council. Retrieved from http://www.englishoutdoorcouncil.org/wpcontent/uploads/Nothing-Ventured.pdf

Heidegger, M. (2001). Zollikon seminars. Evanston, IL: Northwestern University Press.

Hubball, H. T., \& Kennedy, J. (2009). Context-based learning: Research and practice implications in outdoor experiential education. Transformative Dialogues, 3(2), 1-19.

Kabilan, M. K. (2013). A phenomenological study of an international teaching practicum: Preservice teachers' experiences of professional development. Teaching and Teacher Education, 36, 198-209.

Kambutu, J., \& Nganga, L. W. (2008). In these uncertain times: Educators build cultural awareness through planned international experiences. Teaching and Teacher Education, 24(4), 939-951.

Knapp, E., (2012). Place-based education: Listening to the language of the land and people. The Ontario Journal of Outdoor Education, 25(1), 4-6.

Leo-Nyquist, D., \& Theobald, P. (1997, March). Toward a pedagogy of place: Finding common ground for rural researchers, teacher educators, and practitioners. Roundtable Notes. 
Presented at the Annual Meeting of the American Educational Research Association, Chicago, IL.

Lewicki, J.(1998). Cooperative ecology \& place: Development of a pedagogy of place curriculum . (Opinion Paper, 120). Westby, WI: Author. Retrieved from https://eric.ed.gov/?q=ED461461\&id=ED461461

Louv, R. (2005). Last child in the woods. Saving our children from nature-deficit disorder. Chapel Hill, NC: Algonquin Books.

Mannion, G., \& Lynch, J. (2016). The primacy of place in education in outdoor settings. In B. Humberstone, H. Prince, \& K. A. Henderson (Eds.), Routledge international handbook of outdoor studies (pp. 85-94). New York, NY: Taylor \& Francis.

McDonald, M. A., Tyson, K., Brayco, K., Bowman, M., \& Shimomura, F. (2011). Innovation and impact in teacher education: Community-based organizations as field placements for preservice teachers. Teachers College Record, 113(8), 1668-1700.

Miles, M., \& Huberman, M. (1994). Qualitative data analysis: An expanded sourcebook. Thousand Oaks, CA: Sage.

Mollenhauer, K. (1983). Vergessene Zusammenhänge. Über Kultur und Erziehung. München, Germany: Juventa.

Mollenhauer, K. (2014). Forgotten connections: On culture and upbringing. (N. Friesen, Trans.). New York, NY: Routledge.

Mygind, E. (2007). A comparison between children's physical activity levels at school and learning in an outdoor environment. Journal of Adventure Education and Outdoor Learning, 7(2), 161-176. doi: 10.1080/14729670701717580

Pence, H. M., \& Macgillivray, I. K. (2008). The impact of an international field experience on preservice teachers. Teaching and Teacher Education, 24(1), 14-25.

Quezada, R. L. (2004). Beyond educational tourism: Lessons learned while student teaching abroad. International Education Journal, 5(4), 458-465.

Robinson, D. B., \& Bell, R. (2014). A Belizean education: Learning from an international field experience. LEARNing Landscapes, 8(1), 213-231.

Ronfeldt, M. (2012). Where should student teachers learn to teach? Effects of field placement school characteristics on teacher retention and effectiveness. Educational Evaluation and Policy Analysis,34(1), 3-26.

Sahin, M. (2008). Cross-cultural experience in preservice teacher education. Teaching and Teacher Education, 27(7), 1777-1790.

Saevi, T. (2011). Lived relationality as fulcrum for pedagogical-ethical practice. Studies in Philosophy and Education, 30, pp. 455-461.

Selhub, E. M., \& Logan, A. C. (2012). Your brain on nature: The science of nature's influence on your health, happiness and vitality. Hoboken, NJ: John Wiley \& Sons. 
Siljander, P., Kivela, A., \& Sutinen, A. (2012). Theories of bildung and growth: Connections and controversies between continental educational thinking and American pragmatism. Rotterdam, NL: Sense.

Simons, L., \& Cleary, B. (2006). The influence of service learning on students' personal and social development. College Teaching, 54(6), 307-319.

Sobel, D. (2004). Place-based education: Connecting classrooms \& communities. Great Barrington, MA: Orion Society.

Stachowski, L. L., Richardson, W. J., \& Henderson, M. (2003). Student teachers report on the influence of cultural values on classroom practices and community involvement: Perspectives from the Navajo reservation and from abroad. The Teacher Educator, 39(1), $52-63$.

Stachowski, L. L., \& Sparks, T. (2007). Thirty years and 2,000 student teachers later: An overseas student teaching project that is popular, successful, and replicable. Teacher Education Quarterly, 34(1), 115-132.

Stevens, C. (2008). Service learning for health, physical education, and recreation. Champaign, IL: Human Kinetics.

van Manen, M. (1991). The tact of teaching: The meaning of pedagogical thoughtfulness. New York, NY: State University of New York Press.

van Manen, M. (1999). The pathic nature of inquiry and nursing. In Irena Madjar \& Jo Walton, (Eds.), Nursing and the experience of illness: Phenomenology in practice (pp. 17-35). London: Routledge.

van Manen, M. (2015). Pedagogical tact. Walnut Creek, CA: Left Coast Press.

Villegas, A. M. \& Lucas, T. (2002). Educating culturally responsive teachers: A coherent approach. Albany, NY: State University of New York Press.

Willard-Holt, C. (2001). The impact of a short-term international experience for preservice teachers. Teaching and Teacher Education, 17(4), 505-517.

Zelenski, J. M., \& Nisbet, E. K. (2014). Happiness and feeling connected: The distinct role of nature relatedness. Environment and Behavior, 46(1), 3-23.

doi:10.1177/0013916512451901 